\title{
Anything Goes: An Apology for Parallel Distributed Legal Science
}

\author{
JAAP HAGE \\ Universities of Maastricht and Hasselt \\ P.O. Box 616 \\ 6200 MD Maastricht \\ Netherlands \\ jaap.hage@maastrichtuniversity.nl
}

\begin{abstract}
Doctrinal legal science seems to lack a proper method and purpose. This interpretation clarifies its value. The backbone of the argument consists of two theses. The first is that coherence-in a sense unusual in law-plays a crucial role in legal science. The second is that doctrinal legal science is a social enterprise and this should be considered in attempts to understand it. Based on these, a picture of doctrinal legal science is given consisting of parallel distributed constructions of consistent, comprehensive and expansive sets of legal beliefs. Given this, seeming weaknesses of doctrinal legal science turn out to be actual strengths.
\end{abstract}

Résumé: La science juridique doctrinale semble manquer d'une méthode et d'un but appropriés. Cette interprétation clarifie sa valeur. L'épine dorsale de l'argument se compose de deux thèses. La première est que la cohérence - dans un sens inhabituel dans la loi - joue un rôle crucial dans la science juridique. La seconde est que la science juridique doctrinale est une entreprise sociale et cela devrait être pris en compte dans les tentatives pour la comprendre. Fondée sur celles-ci, on qualifie la science juridique doctrinale d'être constituée de constructions parallèles distribuées d'ensembles cohérents, complets et expansifs de croyances juridiques. Compte tenu de cela, les faiblesses apparentes de la science juridique doctrinale se révèlent être des forces réelles

Keywords: coherence, justification, legal science, methodology, world-3 knowledge

\section{Introduction}

Law is an argumentative discipline. Although the focus of theoretical studies in legal argumentation is often on legal decision makers such as law courts, argumentation also plays an important role in the legislative process and in legal science. This contribution deals with the method of argumentation in legal science in general. At first impression such a method seems to be sorely lacking. There are many kinds of legal science, which deal with widely varying research questions, and arguably the relevant method varies with the kind of research question (Smits 
2012, p. 11; Hage 2014). Moreover, doctrinal legal researchwhich is arguably still the core discipline of legal science, certainly on the European continent-seems not to have a clear purpose. Smits (2015) argues that doctrinal research has at least three legitimate aims: description of the existing law, prescription in the sense of a search for practical solutions that fit the existing system best, and justification of existing law. This may be an adequate description of (part of) what actually goes on under the heading of doctrinal research, but it seems to denote a hotchpotch of different kinds of research. Still, doctrinal legal research has a lengthy history, which is a sign that the enterprise of conducting this kind of research is seen as worthwhile.

The aim of this contribution is to give an interpretation of legal science, including doctrinal legal science, which makes the value of this seeming hotchpotch visible. The backbone of this contribution consists of two the theses. The first one is that coherence - in a different sense than is usual in law-plays a crucial role in legal science. The second one that that science, including legal science, is a social enterprise in which people and research groups co-operate in the collection and systematization of knowledge. After a brief discussion of scientific method and methodology in Section 2, the exposition of the coherentist backbone takes up Section 3. Scientific knowledge differs from individual beliefs and this difference requires that the theory of justified subjective knowledge is adapted to make it suitable for knowledge that is more objective in the sense of personindependent. Section 4 deals with the second backbone and is devoted to this difference between individual beliefs and scientific knowledge, and the adaptations it necessitates in traditional epistemology to make it suitable as a theory of justified scientific knowledge. In Section 5 the findings of the two preceding sections are applied to legal science, in an argument that some seeming objections against its practice do not cut ice, and sometimes even represent desirable characteristics. Section 6 concludes the article.

\section{On method and methodology ${ }^{1}$}

Before addressing method in science in some detail, it may be useful to point out a possible terminological confusion between a method and methodology. When considering the nature of scientific method, the first thing that springs to mind is a par-

\footnotetext{
${ }^{1}$ The argument in this section borrows from Hage 2014, which is more elaborate on scientific method.

(C) Jaap Hage. Informal Logic, Vol. 36, No. 3 (2016), pp. 271-287.
} 
ticular way of doing research. A method may contain guidelines on how to conduct an interview, on the statistical techniques that must be used to extract information from a data set, on the tests that need to be performed to diagnose a disease, on the circumstances under which an experiment may be conducted, on the sources and interpretation maxims that must be used to establish a claim in law, and so on ... . All of these guidelines belong to a scientific method indeed, but they do so only in a derived sense. Underneath the guidelines lies a theory about good reasons in scientific discussions. The guidelines are meant to ensure that research in which the guidelines are respected will lead to relevant information concerning the question that the research aims to answer.

A method is in the first place a set of standards by means of which the relevance of arguments can be evaluated. These standards have implications for the way in which scientific research is to be conducted in order to obtain this relevant information. The term 'method' is consequently sometimes also used for the way in which a particular investigation is carried out.

In a critical discussion of the traditional syllogistic model of arguments, Toulmin (1958) developed a scheme that represents the layout of arguments as he saw it. The main idea behind this schema is that the two "premises" in a syllogistic argument fulfil different roles. One premise, represented as "Data", contains factual information. The other premise, represented as "Warrant", indicates that the data are relevant for the conclusion. A legal example would be that the Data contain the information that Harold is a shoplifter, and that the Warrant informs us that shoplifters are punishable. The set of all warrants for the conclusion that somebody is punishable determines the set of facts from which punishability can be concluded. If punishability were to be the sole object of a science, this set of warrants would constitute the primary method for that science. (In practice it is more likely that the science in question would include among its objects also the rules that make behavior punishable, and then its method should also include warrants for establishing the existence (validity) of these rules.)

The existece of this primary method makes it possible to formulate guidelines for collecting data that support a particular conclusion on punishability. Such a guideline might for instance be: collect data that show that somebody did something that was declared punishable in the Penal Code. This guideline would belong to the secondary method of our envisaged science. In this way, the warrants that belong to a particular kind of science, the primary method, determine the secondary method for that domain. 
Warrants are a kind of inference rules. They inform us what can be concluded from particular data, or-the other way round - what kind of data is required in order to support a particular conclusion. Warrants are not descriptive sentences that can be true or false. It is therefore not possible to establish the "truth" of a warrant by means of sensory perception or any other technique to acquire factual information. However, the use of a warrant can be justified by adducing information that links the data to the conclusion of the warrant. Information relevant for justifying the warrant that leads from shop lifting to punishability might for instance be that the Penal Code contains a provision that makes shoplifters punishable. This information consists of data, but Toulmin uses a special name (Backing) for the data that support the use of a warrant. Methodology is the study of data that justify the use warrants in science, or-in the terminology of Toulmin — the study of backings.

\section{On coherentism}

Since a backing consists of data, its relevance must be supported by another warrant. This other warrant also needs to be supported by a backing, made relevant by again some other warrant, and so on ... . The support of warrants by backings and other warrants may lead to an infinite regress, which is familiar from foundationalist approaches in epistemology (Albert 1980, p. 13; Fumerton 2010). A familiar way to avoid such an infinite regress is to abandon the foundationalist approach to scientific method in favor of a coherentist approach (Hage 2013). The main ideas defining a coherentist approach to scientific knowledge in general and to legal knowledge in particular will be sketched in this section. ${ }^{2}$

Just like foundationalism, coherentism is an approach to justification. Where foundationalism seeks to justify claims by tracing them back to some foundation, coherentism adopts as its starting point that justification of a position consists in showing that this position is an element of a coherent position set. In this connection the term 'position' is a catch-all for everything that can mentally be accepted, that is: not only beliefs, assertions,

\footnotetext{
${ }^{2}$ The sketch will be rather informal and superficial, as it is mainly meant to convey some intuitive ideas about the relevance and nature of coherence. More detailed discussions of the present author's views can be found in Hage 2005 and 2013, and - less elaborately - in Hage 2011 and Hage 2015. More general recent discussions of coherentism (in law and elsewhere) are Bonjour 1985, Lehrer 1992, Aarnio e.a 1998, Peczenik 2008, Araszkiewicz and Šavelka 2013 and Amaya 2015.
}

(C) Jaap Hage. Informal Logic, Vol. 36, No. 3 (2016), pp. 271-287. 
and claims, but also mandatory rules, rules of inference, values and policies. Also included - and this will turn out to be important - are hypothetical beliefs, beliefs about what would the case if something else were the case, and meta-beliefs, beliefs about other positions and about the set of all positons accepted by an agent.

The acceptance of a position can be supported or made implausible by other accepted positions that function as reasons for and against the former position. For example, if a person accepts the assertion that John is a thief, this position is supported by the belief that two reliable witnesses declared that they saw John shoplifting and the rule of inference that if two reliable witnesses declare that they saw something happening, this actually happened. The same position is made implausible by the belief that John was elsewhere when the alleged shop lifting took place. The basic intuition of coherentism is that the line of support is not unidirectional, but that positions support each other just like - as a popular metaphor has it - a bundle of sticks that lean against each other and hold each other upright.

Since it is an agent who accepts a position, the justification provided by coherentism is the justification of the agent in accepting (or rejecting) a particular position. In particular it is not justification in the sense of showing a position to be justified in itself. Sometimes the expression 'justified' is used as an alternative for 'truth' in contexts where truth is assumed not to be available. For instance, if one believes that aesthetic judgments are not true or false, one might say that such a judgment is justified. ${ }^{3}$ This sense of being justified is not the justification at issue in coherentism.

That coherentism deals with agents being justified in accepting positions has to do with one of its starting points, namely that the justification for accepting one position must consist in the justification of (the acceptance of) other positions. A belief can, for example, only be justified by other beliefs (and rules of inference), and not by its correspondence to the facts, or by experiences of facts that are not translated into beliefs yet.

\subsection{Strongly justified acceptance}

So the question whether an agent is justified in accepting a particular position depends only on the other position this agents accepts. This leads to the following definition of justified acceptance:

\footnotetext{
3 This theme is elaborated in Hage 2015.

(C) Jaap Hage. Informal Logic, Vol. 36, No. 3 (2016), pp. 271-287.
} 
An agent is strongly ${ }^{4}$ justified in accepting a particular position if and only if:

1. This position is an element of the set of all positions this agent actually accepts (the agent's 'position set').

2. The agent's position set is coherent. Coherence is in this connection defined as the combination of comprehensiveness and consistency.

a. A set of positions is consistent if it does not contain positions that should not be accepted in the light of the rest of the set, and

b. A set of positions is comprehensive if it contains every position that it should contain given the other position it already contains. ${ }^{5}$

The two demands on coherence are the counterparts of the traditional logical concepts of logical consistency and deductive closure. Consistency in the sense used here is a broader notion than traditional logical consistency. Two sentences are logically consistent if they can both be true given the constraints imposed by logic on the sentences that can simultaneously be true. For example, the constraints of logic exclude that the sentences "It's raining" and "It's not raining" are both true. Therefore these sentences are logically inconsistent. The broader notion of consistency at issue here would treat the constraints of logic as positions in a person's position set. This means that the sentences "It's raining" and "It's not raining" are not inconsistent tout court, but only as part of a position set that also includes the logical constraint that a sentence and its negation cannot both be true. On the one hand, it is not automatically given that a position set includes this logical constraint. For an "illogical" person the sentences "It's raining" and "It's not raining" might therefore be consistent. On the other hand, a position set may also contain other constraints, such as physical or conceptual ones, which make that sentences that would logically be consistent are, in combination with these constraints, inconsistent in the light of the full position set. For instance, the sentences "John is a bachelor" and "John is married" may be inconsistent in combination with the conceptual constraint that bachelors are unmarried. As can be seen from these examples, consistency in the sense used here is not a characteristic of limited sets of sentences as in traditional logic, but of a full position set.

\footnotetext{
4 The purpose of the addition 'strongly' will become apparent soon.

5 These two demands on coherence are the counterparts of the traditional logical concepts of logical consistency and deductive closure.
}

(C) Jaap Hage. Informal Logic, Vol. 36, No. 3 (2016), pp. 271-287. 
Just as the new notion of consistency is made relative to the constraints included in the full position set, the notion of comprehensiveness is relative to the full position set too. Whether a sentence should be accepted in the light of what else is accepted depends on, amongst others, the logical demands one makes. What the relevant logical demands (constraints) are depends on the constraints included in the position set. This may vary from one domain to another. For example, in criminal law, the belief (a position) that a suspect is guilty of the crime of which he is accused should only be accepted by a court if there is no reasonable doubt. In private law, the belief that somebody caused a car accident (as support for a claim for damages) should be accepted if the reasons for accepting it are stronger than the reasons against acceptance. So the demand of comprehensiveness works out different in criminal law than in private law, assuming of course that the court's position set includes different rules for criminal and for private law evidence.

An agent's position set is normally incoherent, because the demand of consistency is very strong when a very large set of positions is involved. The limited information processing capacities of the human mind, and the inborn tendencies to be sometimes irrational, are practically a guarantee for the inconsistency of everybody's position set. Therefore no agent will ever be strongly justified in accepting a position. The relevance of the idea of a coherent position set can only be seen as a regulative idea, a paradigm to approximate as much as possible without the chance of ever reaching it.

So what will happen in psychological practice? An agent lives at some moment with an incoherent position set. This set is subject to a continuous series of changes: things that are just forgotten, new beliefs that arise through sensory input, values and attitudes that change as the result of experienced emotions, and so on ... There is also a process going on of making more or less conscious modifications to the set if the agent experiences the set as incoherent. These modifications are aimed at creating more coherence, with a full coherent position set as a regulative idea. The ideal will never be reached, but coherent subsets of limited size are possible.

\subsection{Weaker forms of justified acceptance}

As such, the psychological process is irrelevant for the justification of the elements in an agent's position set. Strong justification is defined in terms of the content of the full position set. However, it is also possible to define weaker forms of justification in terms of the content of subsets of this full position set. 
Such a subset can be coherent in a weaker sense, and this weaker notion of coherence can be used to define weaker forms of an agent being justified in accepting a position:

An agent is weakly justified in accepting a particular position if and only if:

1. This position is an element of some subset $\mathrm{S}$ of the agent's full position set.

2. $\mathrm{S}$ is expansively coherent. Expansive coherence is in this connection defined as the combination of comprehensiveness, consistency and representativeness. S must be

a. consistent.

b. comprehensive.

c. representative: $\mathrm{S}$ contains the belief (a meta-belief) that all elements of S would be present in the agent's full position set if the agent would succeed in making it coherent.

This definition of being weakly justified boils down to it that an agent accepts a position and also believes that he would continue accepting it if he were to succeed in making his position set coherent. In such a situation, the agent is not aware of any sufficient reason that should make him reject the position the now accepts, or should make him collect more information that might change his acceptance.

The above definition of weak justification suggests that there is a binary division between positions that an agent is strongly justified in accepting and positions that an agent is merely weakly justified in accepting. This suggestion is wrong, because weak justification comes in degrees. The smaller the expansively coherent subset, the weaker the justification that can be derived from it. And, the other way round, the bigger the subset, the stronger the justification, with as regulative end point the full position set, which cannot be expansive anymore, and which leads to strong justification.

\subsection{Anything goes}

The definitions given above of an agent being more or less justified in accepting a position refer only to the set of positions the agent actually accepts and a subset thereof. In particular it does not refer to the way in which the agent arrived at accepting these positions. This means that a method in the derived sense of a procedure of gaining knowledge is not relevant for the justification of the knowledge claims. In this sense, Feyerabend (2010, passim) was right when he claimed that in science 'anything goes'. The procedure by means of which an agent arrives at ex-

(C) Jaap Hage. Informal Logic, Vol. 36, No. 3 (2016), pp. 271-287. 
pansively coherent subsets of positions does not matter, as long as these subsets are expansively coherent. This will turn out to be an important observation when we will make the transition, in the next section, from individual agents as holders of position sets to scientific communities.

\section{World-3 knowledge}

Traditional epistemology focuses on knowing individuals and the justification they have in accepting what they accept. This focus can be recognized in the idea of a position set, that was defined as the set of all positions that are actually accepted by a person. However, as Popper (1979, pp. 106-191) already pointed out, such a subjective account cannot do justice to actual scientific practice. Within this practice knowledge has an objective status, not in the sense that it reflects an independently existing world - although Popper also assumed that-but in the sense that it is to some extent detached from the subjective beliefs of individual persons. In this connection Popper distinguished between three "worlds". World-1 would consist of physical objects or physical states, world-2 of states of consciousness, mental states, or perhaps even behavioral dispositions. World-3, then, would consist of objective contents of thought, especially scientific and poetic ones, and of works of art. Science would therefore aim at the production of "world-3 knowledge".

For individual human beings we easily assume that they can access everything that is in their mind and that a knowing subject can at least theoretically process all of his positions to reconstruct them into a coherent set. Even that assumption is dubious, but when we consider knowledge distributed over not only the minds of many persons, but also physical carriers such as libraries and databases, it is obvious that centralized access and reconstruction is a chimaera. Therefore there is reason to adapt theories of knowledge acquisition and justification to make them suitable for scientific knowledge that is stored and processed in a distributed manner.

The practice of scientific publications, through which researchers communicate their findings to others who may build on them or criticize them, can be interpreted as a process aimed at the construction of coherent world-3 knowledge. This process takes place in the minds of many different persons at the same time and it makes use of many different stores of knowledge each of which are shared by some, but not by all knowledge workers. The result is a form of massive parallel distributed processing of information and creation of knowledge. 
Given the vast amount of what is published, and the limited amount of mental capacity to process the produced information, it is highly unlikely that all the available information will ever be consolidated in one fully coherent theory that contains all the scientific knowledge of the world. However, scientific research is for a large part carried out in relatively small communities, the members of which take stock of each other's results by reading each other's publications, by attending the same conferences, and so on. Within these smaller communities, bodies of (temporarily) established knowledge may be developed, which are sometimes laid down in handbooks or teaching materials. There are also researchers who work on the borders of disciplines, for example mathematically oriented biologists or historically interested comparative lawyers, who can transfer knowledge from one knowledge community to another community. The newly acquired knowledge may then be used within these communities to reconstruct the temporarily established body of coherent knowledge into a new weakly coherent body, in which the new information has been incorporated.

Because larger subsets of positions lead to better justified knowledge than smaller subsets, there will be a tendency to incorporate local theories in wider ones. Since these wider theories still need to be weakly coherent, there will also be an urge to systematize the available knowledge, in an attempt to show that everything fits nicely together.

There is still much more that can and needs to be said about parallel knowledge production in a distributed environment, but for our present purposes the above must suffice. In the next section the question will be addressed what the idea of parallel distributed knowledge production means for legal scientific research.

\section{Legal scientific research}

This article started with the observation that legal scientific research sometimes seems a hotchpotch, both where the research questions are concerned and where the aims and methods are at stake. Since legal research, and in particular doctrinal research has a long history, which suggests that the activity is broadly considered to be sensible, there is something that needs to be explained. In the previous sections an account of scientific research was developed around two backbones. The one is that positions, including beliefs about law, are justified if and to the extent that they are part of coherent sets. The second is that scientific knowledge is, in Popper's terminology, world-3 
knowledge, which has some independence of the beliefs of individual scientific researchers. This knowledge is both stored and processed in a distributed and parallel way.

When we look at actual legal research, a number of its characteristics draws attention:

1. Legal research covers many different traditional fields of research, including sociology, psychology, biology, economy, game theory, history, philosophy, literature, and computer science. Next to these 'Law and ...'-approaches there is also doctrinal legal research.

2. The aims of legal research are manifold, or - less kindly stated - not well-defined.

3. Scientific publications 'mix up' different approaches, such as description, evaluation and prescription.

4. The proper 'methods' of legal science are disputed.

5. Legal publications often seem to be little more than comments on recent events, such as new legislation, new case law, or historical events that seem to have implications for law, such as the present refugee crisis.

Can these characteristics be explained, and even justified? We will address them one by one.

\subsection{Many fields of legal research}

Legal research is characterized by its object, which is law. This object can be approached from different angles, and given the importance of law within our society it should not create surprise if many different angles turn out to be used for studying the law. However, this does not justify that these different angles are often mixed up in a single publication. It is, for example, not uncommon that a monograph on, say, the right to privacy, addresses the history of this right, the different ways it is protected in national constitutions, data protection acts, and human rights treaties, its elaboration in case law of both national and international courts, its impact on practices of governmental and non-governmental organizations, and the desirability of its further development. However - and here the coherentist approach to knowledge enters the picture-theories about law, whether they are sociological, historical, or doctrinal, or still from another angle, are ideally part of a comprehensive theory which encompasses all our knowledge. Therefore it is not only possible, but even desirable, that the legal sciences include many different approaches. It would be even more desirable if the different approaches would lead to many-faceted theories of law, 
that combine the different research angles. Perhaps both the history of a right and its impact on society should influence its further development, and perhaps there should be a relation between the ways in which a right is codified and its elaboration in case law. In such cases, 'mixed' legal publications might be evidence of broad legal thinking, which is to be applauded, rather than a sign of confusion.

\subsection{Several aims}

Different disciplines have their own aims. Even "hard" sciences such as mathematics, biology and physics can pursue different aims, and it is also possible that one science pursues more than one aim. Physics is for instance used for explanatory, predictive and engineering purposes. Law can be described, but it can also be evaluated, for example for legislative purposes. The fact that the legal sciences pursue different aims, and perhaps sometimes several aims at once, is therefore not necessarily problematic.

Moreover, the different aims of a science do not have to exclude each other. A famous example is the HempelOppenheim model of explanation and prediction (Hempel 1965, 245-295), which serves, as the name indicates, the dual function of explaining and predicting. An evaluation of the law can be part of, or lead to, a particular description of the law. This would for instance be the case if law is treated as a functional kind (Fuller 1963 and Moore 1992), when something can only be fully law if it succeeds in fulfilling the functions of law, or if law is seen as the best possible reconstruction of a combination of legal sources and moral judgments (Dworkin 1986). The same holds for a historical description of how a particular legal doctrine developed in the course of time, which may be seen as relevant for the proper interpretation for contemporary law (Alexy 1983, p. 294).

Also in this connection it is relevant to point out that theories about law, for whatever aim they were created, are ideally part of an all-encompassing theory. This bigger theory should also deal with the aims of the different legal sciences and the ways in which the results of these sciences are also relevant for related disciplines. In a coherent theory the results of one discipline may have implications for theories other disciplines, but such a coherent theory may also include the position that, for instance, moral considerations are not relevant for the content of the law (Raz 1986, pp. 57-62; Marmor 2002). Coherence brings in this connection along that such a meta-theory about the relevance of disciplines for each other is reflected in the results of 
these disciplines. A description of the law would, for instance, not be based on moral considerations.

\subsection{Disputed method}

It should not come as a surprise that the proper methods for doing legal research are disputed. There are at least two reasons why such disagreement should exist. One reason is that the best way to conduct research on a particular knowledge object depends on the view one has about the nature of the object. This is particularly clear in the case of law.

Many lawyers see law as a social phenomenon which should be studied as such. On this view, the proper way to study the law is the way in which one should study a social phenomenon. This view is at least suggested by Hart in the Preface of his The concept of law (Hart 2012, p. vi) But then there exists also disagreement about the proper way for studying social phenomena. Some prefer an approach that is similar to the one used in the physical sciences; others prefer an approach focused on rational choice theory and understanding. ${ }^{6}$ Interpretation may play an important role in this connection too (Dworkin 1986, Aarnio 1987).

Other lawyers see law as part of the broader enterprise of practical reasoning or even critical morality. The content of law is then a matter of normative reasoning (Finnis 2011, pp. 23-45), and description and interpretation only play a role to the extent that they provide data that are relevant for this normative reasoning (Raz 1979). What the proper method for practical and moral reasoning is, is also a matter of dispute, but following Rawls (1972) some variant on coherentism - reflective equilibrium (Daniels 2011) — has become quite popular.

On a very abstract level, anything goes in all branches of knowledge acquisition, and therefore also in the legal sciences. On a somewhat more concrete level it is important that the positions which one adopts concerning the nature of law and the method for legal science are consistent. Since there are different viable theories about the nature of law, there are also different viable theories on what is the proper method for legal science. The demand made by coherentism is merely that one's view of law and one's preferred method of doing legal science cohere. The fact that the proper method for doing legal science is disputed therefore does not have to be interpreted as a sign that there is something wrong with legal science.

\footnotetext{
${ }^{6} \mathrm{Cf}$. the different approaches presented and described in Rudner 1966, Ryan 1970 and Benton and Craib 2001.

(C) Jaap Hage. Informal Logic, Vol. 36, No. 3 (2016), pp. 271-287.
} 


\subsection{Reactive science}

Many legal doctrinal publications seem to be mere reflections on recent events, rather than attempts to build a coherent body of knowledge. This appearance might be misleading, however, since the recent events may disturb the coherence of a subtheory, or evoke questions that require legal answers, while existing sub-theories do not provide the required answers yet. In a sense, the events to which legal doctrine reacts can be compared to new positions that are spontaneously inserted into the position set of an individual person, for example because of sensory perception, or reading some new information. This new information must receive its place in this person's position set, or should be removed again because it is incompatible with the present content of the set and should, according to guidelines for belief revision contained in the set, be sacrificed to the existing positions. Analogously, "disturbing" events must be given a place in the existing body of scientific knowledge (read: the prevalent sub-theory), either by expanding the theory to make it answer new questions, of by modifying it to incorporate new legislation or case law, or by ignoring the new events. In this sense legal doctrinal research is as much maintenance of the legal system as it is collection of knowledge. That the same thing can be both maintenance of the knowledge object (the law) as well as collection of knowledge about the object presumes that some knowledge object, including the law, depend on our knowledge of it. This is a familiar theme in ethical theory under the heading of constructivism (Bagnoli 2015), and its implications for law deserve further exploration (see Hage 2013).

\section{Conclusion}

We see that all five characteristics of legal science which seemed at first sight troublesome can be justified or at least explained if one assumes a coherentist, world-3 theory of legal science. The sketch of such a theory that was offered above is hardly more than the bare outlines. In particular the implications of a world-3 theory of scientific knowledge for coherentism need elaboration. How, for instance, can coherentism account for the phenomenon that there exist different incompatible opinions within a particular field of science and that some researchers are not willing to abandon their views, even if they are minority ones? Accounts of scientific development, such as those of Popper (2002), Kuhn (2012), Lakatos (1970), Feyerabend 
(2010), Laudan (1992) and also Latour (1987) need to be given a place in a coherentist framework.

Some of these accounts - in particular those of Kuhn, Feyerabend and Latour-emphasize that scientific progress is not fully - or not at all - a matter of reason. Social interactions play a role, since science is - otherwise than the development of a single person's position set-also a social process. Obviously, legal research is in this respect no different than other kinds of scientific research. The challenge is therefore to create circumstances for doing legal research that promote the rational outcome of the process (Goldman 1999). Somehow the contributions made by many different researchers that have different agenda's must be reconstructed into a coherent position set. How to meet that challenge is a worthy research question for future research. In this article we have seen grounds for assuming that the present state of legal science may be not as bad as it might seem at first sight.

\section{References}

Aarnio, Aulis. 1987. The rational as reasonable. a treatise on legal justification. Dordrecht. Reidel.

Aarnio, Aulis, Robert Alexy, Aleksander Peczenik, Wlodek Rabinowicz and Jan Wolenski 1998. On coherence theory of law. Lund. Juristförlaget.

Albert, Hans. 1980. Traktat über kritische Vernunft. Tübingen. Mohr.

Alexy, Robert. 1983. Theorie der juristischen Argumentation, $8^{\text {th }}$ edition ( $1^{\text {st }}$ ed. 1978). Frankfurt. Suhrkamp.

Amaya, Amalia. 2015. The tapestry of reason. Oxford. Hart.

Araszkiewicz, Michal and Jaromir Šavelka (eds.). 2013. Coherence: insights from philosophy, jurisprudence and artificial intelligence. Dordrecht. Springer.

Bagnoli, Carla. 2015. Constructivism in metaethics. In Edward N. Zalta (ed.), The Stanford encyclopedia of philosophy (Spring 2015 Edition). http://plato.stanford.edu/archives/win2011/entries/constructiv ism-metaethics.

Benton, Ted and Ian Craib. 2001. Philosophy of social science. Houndmills. Palgrave.

Bonjour, L. 1985. The structure of empirical knowledge. Cambridge. Harvard University Press. 
Daniels, Norman. 2011. Reflective equilibrium. In Edward N. Zalta (ed.), The Stanford encyclopedia of philosophy (Spring 2011 Edition), http://plato.stanford.edu/archives/spr2011/entries/reflectiveequilibrium.

Dworkin, Ronald. 1986. Law's empire, London. Fontana.

Feyerabend, Paul. 2010. Against method, $4^{\text {th }}$ edition, $\left(1^{\text {st }}\right.$ edition 1975). London. Verso.

Finnis, John. 2011. Philosophy of law. collected essays: volume $I V$. Oxford. Oxford University Press.

Fuller, Lon L. 1963. The morality of law, revised edition, New Haven. Yale University Press.

Fumerton, Richard. 2010. Foundationalist theories of epistemic justification. In Edward N. Zalta (ed.), The Stanford encyclopedia of philosophy (Summer 2010 Edition). http://plato.stanford.edu/archives/sum2010/entries/justepfoundational.

Goldman, Alvin I. 1999. Knowledge in a Social World. Oxford. Clarendon Press.

Hage, Jaap. 2005. Law and coherence. In Jaap C. Hage, Studies in legal logic, 33-68. Dordrecht. Springer

Hage, Jaap 2011. The Method of a Truly Normative Legal Science. In Mark van Hoecke (ed.), Methodologies of legal research, 19-44. Oxford. Hart.

Hage, Jaap. 2013. Three kinds of coherentism. In Michal Araszkiewicz and Jaromir Šavelka (eds.), Coherence: Insights from philosophy, jurisprudence and artificial intelligence, 1-32. Dordrecht. Springer.

Hage, Jaap. 2014. Comparative law as Method and the Method of Comparative Law. In Maurice Adams and Dirk Heirbaut (eds.), The method and culture of comparative law, 37-52. Oxford. Hart.

Hage, Jaap. 2015. The Justification of Value Judgments. Theoretical Foundations for Arguments about the Best Level to Regulate European Private Law. In Bram Akkermans, Jaap Hage, Nicole Kornet and Jan Smits (eds.), Who does what? on the allocation of regulatory competences in European private law, 15-56. Cambridge. Intersentia.

Hart, H.L.A. 2012. The Concept of Law, $3^{\text {rd }}$ edition $\left(1^{\text {st }}\right.$ ed. 1961). Oxford. Oxford University Press.

Hempel, Carl G. 1965. Aspects of scientific explanation. New York. The Free Press.

Kuhn, Thomas S. 1970. The structure of scientific revolutions, $2^{\text {nd }}$ edition $\left(1^{\text {st }}\right.$ ed. 1962). Chicago. The University of Chicago Press. 
Lakatos, Imre. 1970. Falsification and the methodology of scientific research programs. In I. Lakatos and A. Musgrave (eds.), Criticism and the growth of knowledge, 91-196. Cambridge. Cambridge University Press.

Latour, Bruno. 1987. Science in action. Cambridge. Harvard University Press.

Laudan, Larry. 1992. Progress and its problems. towards a theory of scientific growth $\left(2^{\text {nd }}\right.$ edition $\left(1^{\text {st }}\right.$ ed. 1977). Berkley: University of California Press.

Lehrer, Keith. 1992. Coherentism. In Jonathan Dancy and Ernest Sosa (eds.), A companion to epistemology, 67-70. Oxford. Blackwell.

Marmor, Andrei. 2002. Exclusive legal positivism. In Jules Coleman and Scott Shapiro (eds.), The Oxford handbook of jurisprudence and philosophy of law, 104-124. Oxford. Oxford University Press.

Moore, Michael 1992. Law as a functional kind. In Robert P. George (ed.), Natural law theory, 188-242. Oxford. Clarendon Press.

Peczenik, Aleksander 2008. On law and reason, $2^{\text {nd }}$ edition $\left(1^{\text {st }}\right.$ ed. 1989). Dordrecht. Springer.

Popper, Karl R. 1979. Objective knowledge. an evolutionary approach, revised edition (1st ed. 1973). Oxford. Oxford University Press.

Popper, Karl R. 2002. The logic of scientific discovery, $2^{\text {nd }}$ edition ( $1^{\text {st }}$ ed. 1959). London. Routledge.

Rawls, John. 1972. A theory of justice. Oxford. Oxford University Press.

Raz, Joseph. 1979. The authority of law. Oxford. Clarendon Press.

Raz, Joseph. 1986. The Morality of Freedom. Oxford. Clarendon Press.

Rudner, Richard S. 1900. Philosophy of social science. Englewood Cliffs. Prentice Hall.

Ryan, Alan. 1970. The philosophy of the social sciences. London. MacMillan.

Smits, Jan M. 2012. The mind and method of the legal academic. Cheltenham. Edward Elgar.

Smits, Jan M. 2015. What is legal doctrine? On the aims and methods of legal-dogmatic research. Maastricht European Private Law Institute working paper no. 2015/06, http://papers.ssrn.com/sol3/papers.cfm?abstract_id=2644088 (last visited on October 28, 2015).

Toulmin, Stephen 1958. The layout of arguments. In his The uses of argument, 94-145. Cambridge. Cambridge University Press. 